\title{
A PESQUISA PSICANALÍTICA E SUAS RELAÇÕES COM A UNIVERSIDADE ${ }^{1}$
}

\section{CAMILA SANTOS LIMA FONTELES; DENISE MARIA BARRETO COUTINHO; CHRISTIAN HOFFMANN}

\author{
Camila Santos Lima \\ Fonteles \\ Universidade Federal \\ da Bahia (UFBA), \\ doutora pelo Instituto \\ de Psicologia, \\ Programa de Pós- \\ Graduação em \\ Psicologia, \\ Salvador/BA, Brasil. \\ Cotutela com a \\ Universidade Paris \\ Diderot - Paris 7, Paris, \\ França.

\section{Denise Maria Barreto} \\ Coutinho \\ Universidade Federal \\ da Bahia (UFBA), \\ professora associada \\ do Instituto de \\ Psicologia, Programa \\ de Pós-Graduação em \\ Psicologia, \\ Salvador/BA, Brasil.

\section{Christian Hoffmann} \\ Universidade Paris- \\ Diderot, Paris VII, \\ professor e diretor da \\ Escola Doutoral de \\ Pesquisas em \\ Psicanálise, \\ Laboratório \\ Psicanálise, Medicina e \\ Sociedade, Paris, \\ França.
}

\begin{abstract}
RESUMO: Este artigo tem como objetivo discutir o lugar da pesquisa em psicanálise no campo psicanalítico bem como na universidade. A psicanálise se constitui na dimensão de pesquisa, reformulando-se continuamente como atesta o legado de Freud. Uma parte das produções psicanalíticas na universidade brasileira (teses) foi analisada em seus métodos e referenciais teóricos para discutirmos a interface pesquisa, psicanálise e universidade. A diversidade de métodos, temas, autores e de articulações aos saberes diversos, aliada ao caráter de inacabamento, constitutivo do referencial psicanalítico, permite dizer que, na universidade, lócus tradicional da pesquisa, a psicanálise pode ser formulada e também reinventada.
\end{abstract}

Palavras-chave: pesquisa psicanalítica; universidade brasileira; teses.

\begin{abstract}
Psychoanalytic research and its relations with the university. This article aims to discuss the place of psychoanalytic research in the psychoanalytic field as well as at the university. Psychoanalysis constitutes in the dimension of research and reformulates continuously as evidenced by the legacy of Freud. A part of psychoanalytic productions in Brazilian universities (thesis) was analyzed in its methods and theoretical frameworks to discuss the interface research, psychoanalysis and university. The diversity of methods, themes, authors and articulations to several areas of knowledge, coupled with the character of incompleteness, constitutive of psychoanalysis, allows us to say that the university, traditional research locus, psychoanalysis can be formulated and also reinvented.
\end{abstract}

Keywords: psychoanalytic research; Brazilian university; thesis.

DOI - http://dx.doi.org/10.1590/1809-44142018001013

\footnotetext{
${ }^{1}$ Este trabalho é parte da tese de doutorado da primeira autora, orientada pelos dois coautores, intitulada Psicanálise $e$ universidade: uma análise da produção acadêmica no Brasil, defendida em 2015 no Programa de Pós-Graduação em Psicologia da Universidade Federal da Bahia em cotutela com a Université Paris Diderot - Paris 7 (França).
} 


\section{INTRODUÇÃO}

Somente aqueles crédulos, que exigem da ciência um substituto para o catecismo abandonado, se aborrecerão com o pesquisador por desenvolver ou modificar seus pontos de vista.

Sigmund Freud, Além do princípio do prazer.

Neste comentário em epígrafe, Freud reconhece o caráter transformador da investigação inerente à práxis psicanalítica e antecipa elementos epistemológicos da pesquisa científica contemporânea. Sua proposta, desde os primeiros escritos, aponta para a presença do "terceiro incluído", ao lidar na clínica com relatos de sentimentos contraditórios - como amor e ódio, sem, com isso, supor alguma patologia - e ao considerar os múltiplos níveis de realidade (que incluem a realidade material e a realidade psíquica), mais explicitados por meio do conceito de sobredeterminação que ele desenvolve desde seus primeiros escritos. Tais rupturas indicam que a psicanálise inscreve-se com marca epistêmica própria em relação às ciências dominadas pelo modelo cartesiano-positivista do final do século XIX e durante boa parte do século XX.

Por outro lado, é inegável também que a psicanálise insere-se na ciência do seu tempo, referindo muitas vezes à física e à química para forjar conceitos à luz de inferências e leis ditas naturais. Freud pagou um preço alto por reivindicar um método próprio que conjuga produção de conhecimento, isto é, teoria, com modo de tratamento e de investigação. Na condição de práxis, propõe-se a escutar o sujeito do inconsciente, que se apresenta no inesperado e fugaz das experiências singulares e, ao mesmo tempo, universais de cada ser humano. Esta intenção epistemo-metodológica própria representa um vinculo indelével (porém, às vezes, ambivalente) com a instituição socialmente legitimada para a produção do conhecimento canônico na sociedade ocidental: a universidade.

O novo objeto trazido pela psicanálise para o âmbito das ciências, o conceito de inconsciente, e uma nova forma de pesquisa com método próprio caracterizam a especificidade deste campo que, desde o início de sua constituição, pleiteia - e realiza - inserção no ambiente universitário, juntamente com as demais disciplinas científicas. Portanto, este artigo tem como objetivo discutir o lugar da pesquisa em psicanálise, seja ela realizada em instituições psicanalíticas ou na universidade, a partir da análise de parte da sua produção acadêmica.

No contexto da produção de conhecimento, deparamo-nos muitas vezes com a tentativa conservadora e cartesiana de adaptação das pesquisas a um modelo universal de ciência. Freud ultrapassa o ideal cartesiano, advogando um método próprio, além de ter combatido veementemente a atribuição de falta de rigor da psicanálise. Ele defende a localização da psicanálise no campo das ciências naturais, sem deixar de aproximá-la das ciências humanas.

Além disso, recorre a diversos saberes para constituir a psicanálise, relacionando-a também a vários outros campos. Tal conformação interdisciplinar é característica do campo desde seus primórdios. Trata-se, portanto, de um campo que inclui uma diversidade de saberes constitutivos, posicionamento divergente do hegemônico sobre o estatuto e a própria definição de ciência e pesquisa imbricada com teoria, tratamento e labor clínico.

\section{A PESQUISA NA GÊNESE DO CAMPO PSICANALÍTICO}

Na condição de médico neurologista, Freud esteve em contato com atividades científicas desde sua formação universitária em Viena. O início de sua carreira ocorre no laboratório de fisiologia de Ernst Brücke, onde trabalha com sistema nervoso de animais inferiores, o que the proporciona familiaridade com procedimentos de investigação científica de sua época. No texto Autobiografia (1925/2011), ele relata sua imersão nas pesquisas científicas do referido laboratório, passando aos estudos com Josef Breuer e, na França, com Jean-Martin Charcot. 
Podemos destacar algumas passagens na obra freudiana que demonstram o lugar da pesquisa, entrelaçando tratamento e teoria e caracterizando a psicanálise como práxis. Em Recomendações ao médico que pratica a psicanálise, Freud afirma: “Um dos méritos que a psicanálise reivindica para si é o fato de nela coincidirem pesquisa e tratamento" (1912/2010, p. 153), argumentando que a pesquisa em psicanálise diz respeito a cada caso específico e não a um experimentalismo. Tal modelo, inicialmente pautado na clínica médica, na qual o caso é o particular de um universal, constitui ruptura na relação tradicional entre universalparticular, instaurando outra lógica: a do caso em sua singularidade, sem referência necessária a um universal.

É o que nos diz Freud: “Assim ocorreu que a psicanálise, uma técnica puramente médica em sua origem, viu-se desde o começo direcionada para a pesquisa, para o descobrimento de nexos amplos e ocultos" (FREUD, 1919/2010, p. 390), concordando com o que ele relata anteriormente em Princípios básicos da psicanálise:

A psicanálise é uma disciplina singular, em que se combinam um novo tipo de pesquisa das neuroses e um método de tratamento com base nos resultados daquele. Desde já enfatizo que ela não é fruto da especulação, mas da experiência, e, portanto, é inacabada enquanto teoria. Mediante suas próprias inquirições, cada qual pode se persuadir da correção ou incorreção das teses nela presentes, e contribuir para seu desenvolvimento. (FREUD, 1913/2010, p. 269)

Ressaltamos que a pesquisa a que Freud se refere, em diversos momentos de sua obra, difere da pesquisa ordinariamente realizada no ambiente acadêmico, na qual importa sobremaneira o que disso resulta em capital simbólico e financeiro para alimentar mais pesquisas e fazer a engrenagem universitária funcionar, quase sempre no apagamento e invisibilização de sujeitos ali implicados. Trata-se aqui da inquietação que problematiza e busca por novos conhecimentos, mas também novas dúvidas, e reconhece a cada vez o inacabado da tarefa, como ele sublinhou tão bem. Freud empreende um tipo de investigação do psiquismo jamais enfrentado. O que nos interessa aqui é o caráter de investigação, a abertura ao novo e a sustentação do caráter inacabado, faltoso, da pesquisa e da produção de conhecimentos, presente desde os primeiros textos freudianos e que deveriam também pautar a formação universitária e as pesquisas acadêmicas.

A dimensão da pesquisa lhe é não somente cara, mas indispensável à "nova disciplina científica". Lembremos também que ele publica seus casos clínicos e os deixa como legado e prova dessas articulações entre clínica e pesquisa, conforme explicita em $A$ questão da análise leiga:

Na psicanálise tem existido desde o início um laço inseparável entre cura e pesquisa. O conhecimento trouxe êxito terapêutico. Era impossível tratar um paciente sem aprender algo de novo; foi impossível conseguir nova percepção sem perceber seus resultados benéficos. Nosso método analítico é o único em que essa preciosa conjunção é assegurada. (FREUD, 1926/1996, p. 246)

Para responder à crítica de que a teoria psicanalítica é pouco clara e abstrata, Freud argumenta que os conceitos de uma ciência são fruto de seu desenvolvimento ao longo dos anos. Em Introdução ao narcisismo (1914/2010), considera imprescindível para qualquer ciência não baseada na pura especulação, conceitos flexíveis e refutáveis, que possam ser substituídos à medida que o conhecimento avance, o que ele já afirmava um ano antes em Princípios básicos da psicanálise (1913/2010), ao dizer que a psicanálise é inacabada enquanto teoria, sendo, portanto, aberta ao novo e às reformulações que a pesquisa e a prática clínica proporcionam.

Posteriormente, em Os instintos e seus destinos (1915/2010), ele retoma a mesma ideia, dizendo que nenhuma ciência, nem mesmo a mais exata, começa com termos claros e bem definidos, ressaltando que o primeiro objetivo de uma atividade científica consiste na descrição do fenômeno, aplicando-se-lhe ideias abstratas. Diz Freud: "Mas o progresso do conhecimento também não tolera definições rígidas. Como ilustra de maneira excelente o exemplo da física, também os 'conceitos fundamentais' fixados em definições experimentam uma constante alteração de conteúdo" (1915/2010, p. 52-53). 
No texto Psicanálise e teoria da libido, num trecho que intitula Caráter da psicanálise como ciência empírica, Freud diz ainda:

A psicanálise não é como um sistema filosófico, que parte de conceitos fundamentais claramente definidos, procura com eles apreender o mundo como um todo e depois, quando completado, não tem mais lugar para novos achados e melhores percepções. Ela se atém aos fatos do seu âmbito de trabalho, busca solucionar os problemas imediatos trazidos pela observação, segue tateando com base na experiência, está sempre incompleta, sempre disposta a ajustar ou modificar suas teorias. Tal como a física e a química, ela tolera muito bem que seus principais conceitos sejam vagos e seus pressupostos sejam provisórios, e espera uma maior precisão deles como resultado do trabalho futuro. (FREUD, 1923/2011, p. 301)

Para Assoun (1978), Freud inscreve a psicanálise no paradigma epistemológico que se estruturou de acordo com o modelo da física relativista. A indeterminação e a possibilidade de revisão dos conceitos são plenamente compatíveis com o rigor científico. Tal como a física e a química, citadas por Freud, a psicanálise também modifica teoria e técnica em função da experiência. Daí, seu afastamento da filosofia, visto que, para Freud, o sistema filosófico é caracterizado pela ambição de conceber a totalidade do mundo, de se pretender acabado, não deixando espaço para novas descobertas.

\section{A PESQUISA PSICANALÍTICA E SUA INSTITUCIONALIZAÇÃO}

A institucionalização da psicanálise, com a criação da IPA em 1910, ainda que comandada por Freud para regulamentar a formação do analista e difundir a psicanálise, contribuiu para deixar a pesquisa esquecida durante muitos anos nas instituições, como afirma Colonomos (1985), que também interroga como se poderia pensar a criatividade essencial para a pesquisa no contexto de rigidez que era o da IPA.

Hoffmann (2013) cita um artigo de Hans Sachs (um dos primeiros analistas didatas) de 1939, intitulado As perspectivas da psicanálise, no qual há uma crítica às instituições da época. Uma instituição tem por objetivo garantir sua sobrevivência, como toda e qualquer outra, padronizando condutas. Então, se uma instituição é criada visando à padronização e se a pesquisa tem como objetivo fazer emergir novas questões, a contradição mostra-se inevitável. No pensamento de Sachs, o sucesso da psicanálise no campo científico não poderia continuar sem produzir variações no método, sobretudo onde a associação livre, regra fundamental da análise, não pode ser aplicada, a saber, à psicanálise com crianças e no estudo dos fenômenos sociais. Portanto, a psicanálise não pode negligenciar o divórcio existente entre pesquisa e uma instituição conservadora.

Ao mesmo tempo em que a IPA é criada para proteger a psicanálise e manter o método freudiano, tem também como objetivo declarado ser um lugar de trocas, de pesquisas e de criação de novas vias na psicanálise (WIDLÖCHER, 2007). Os institutos de psicanálise tinham como preocupação primordial uniformizar práticas, sistematizar a formação, evitar novas rupturas e a "produção superegoica de uma geração de analistas obedientes" (KUPERMANN, 2014, p. 74). Nas palavras de Sokolowsky (2009), referindo-se ao Instituto de Berlim (primeira instituição formadora criada em 1920 e que serviu de modelo para as demais), somente os mais dóceis teriam chances de ser selecionados como candidatos a analistas. Para a autora, regras rígidas e a padronização da formação na instituição acabaram por suplantar sua originalidade inicial como local de acesso amplo à psicanálise. O movimento psicanalítico se dogmatiza para proteger a psicanálise, o que não deixa de ser uma contradição com o caráter transgressivo e inovador dela.

Desse modo, até a década de 1980, a pesquisa não era visada pelos institutos e escolas de psicanálise, estando essa atividade restrita a congressos e publicações. A partir de 1985, a política da IPA muda e a pesquisa empírica passa ser alvo de atenção, sob o argumento de que a psicanálise não sobreviveria sem esse tipo de investigação, diante do contexto de contestação da eficácia de sua clínica. O intuito era mostrar que, por meio da pesquisa, seria possível fazer progredir teoria e prática (WIDLÖCHER, 2007). 
A pesquisa psicanalítica é um tema controverso e que suscita indagações. Cada um aborda a prática da pesquisa de acordo com sua formação, trajetória intelectual e profissional no campo. A despeito de novos dispositivos e de uma quase infinidade de temas de pesquisa, esse modelo, pautado na clínica, permanece como referência, o que nos leva a retomar sua efetiva aplicação na universidade.

\section{A PESQUISA EM PSICANÁLISE NA UNIVERSIDADE}

A universidade brasileira segue remotamente o modelo da universidade de pesquisa, sobretudo na pósgraduação, lugar privilegiado do seu desenvolvimento. De acordo com Sousa-Santos e Almeida-Filho (2008), a instituição universitária, no decorrer da sua história, conheceu diferentes modos de constituição: a universidade escolástica, a universidade clássica, a universidade vocacional e a universidade de pesquisa a partir da reforma Humboldt. A universidade até o século XIX era conservadora e a pesquisa era realizada nas academias, museus e sociedades científicas. Portanto, a produção do conhecimento, característica maior da universidade, aparece a partir da universidade de pesquisa. Ainda segundo os autores, a universidade brasileira é herdeira dos modelos das universidades europeias do século XIX. Além disso, sofreu com as reformas do período da ditadura militar, que impôs o sistema de departamentos, sobreposto ao sistema de cátedras vitalícias, e, na década de 1990, vivencia uma intensa e significativa ofensiva neoliberal de abertura ao setor privado. Constata-se como resultado desse processo que: "a universidade brasileira terminou dominada por um poderoso viés profissionalizante, com uma concepção curricular simplista, fragmentadora e distanciada dos saberes e das práticas de transformação da sociedade" (SOUSA-SANTOS; ALMEIDA-FILHO, p. 194). A arquitetura universitária brasileira é, portanto, confusa e arcaica, sem correspondente na maior parte dos países do mundo, tendo como características múltiplas titulações, programas sem articulação entre si, pouco flexíveis e "distantes de cumprir o mandato histórico da universidade como formadora da inteligência e da cultura nacional" (ibidem, p. 194).

Curiosamente, no Brasil a exigência de indissociabilidade ensino-pesquisa-extensão é constitucionalmente estabelecida desde 1988, o que contrasta com o também constitucional princípio de autonomia das universidades. Fazem exceção, no sentido de uma relação de fato produtiva, os programas de iniciação científica que desempenham papel indutor da pesquisa na graduação e o sistema nacional de pósgraduação, lugar por excelência da pesquisa universitária. Nesse cenário, destaca-se também a figura dos laboratórios de pesquisa, que descentram a figura do professor, apoiam a graduação e, dessa forma, propiciam um ensino orientado pela pesquisa, fornecendo-lhe uma perspectiva de produção e não mera reprodução de conhecimentos.

Para Hoffmann e Birman (2011), a pesquisa seria, de forma indiscutível, elemento estruturante desse tipo de universidade. Ao posicionar a pesquisa como ponto de partida e de ancoragem institucional, deslocase a posição do docente e do estudante e instaura-se um espaço de trocas, com lugares menos personalizados e centrados na figura do mestre. A pesquisa coloca o saber em uma posição terceira na relação ensinoaprendizagem, favorecendo a postura ativa pela construção e apropriação do conhecimento, tanto do docente quanto do discente. A psicanálise, presente na universidade, tem papel importante a desempenhar no cenário de tal configuração político-acadêmica. A pesquisa pode, então, interrogar não apenas o conhecimento, mas também o saber, figura imaterial, porém materializável na medida em que incorporado, isto é, corporificado por alguém que, em relação, produz e interroga a teoria, relançando as bases de novos conhecimentos.

As aproximações com o meio universitário acentuam ainda mais tais questões, uma vez que a universidade pressupõe métodos consagrados e um estilo de escrita muitas vezes diferente do que os psicanalistas estão habituados a utilizar na instituição psicanalítica que é, também, um lugar de pesquisa. Atualmente, no Brasil, existem importantes periódicos científicos provenientes das universidades e de escolas 
de psicanálise, indexados e avaliados pela Coordenação de Aperfeiçoamento de Pessoal de Nível Superior (Capes).

Ressaltamos algumas divisões que se estabeleceram e que serão importantes para compreender, em seguida, o material a ser aqui apresentado. Trata-se da famosa distinção entre pesquisas em psicanálise e pesquisas sobre psicanálise, sendo a primeira realizada a partir de material clínico e do método analítico e a segunda sobre questões que interessam à psicanálise, não necessariamente conduzida por analista, articulando a psicanálise com outros campos, com diferentes recursos metodológicos, e cujos resultados podem ser compreendidos à luz de conceitos da psicanálise. Esta divisão remonta ao texto Deve-se ensinar a psicanálise nas universidades? (FREUD, 1919/2010) em que, ao discutir a presença desse ensino, Freud distingue o aprender sobre e com a psicanálise. Também está relacionada ao que Lacan diz na Proposição de 9 de outubro de 1967 sobre o psicanalista da escola, no que concerne à divisão da psicanálise em extensão e em intensão, sendo a primeira aplicações da psicanálise e a segunda derivada da clínica e relacionada à formação do analista, embora indissociáveis (FIGUEIREDO, 2008).

Para Lacan não há, pois, separação entre os dois termos, mas junção. Mais que junção, há orgânica continuidade: "De conformidade com a topologia do plano projetivo, é no próprio horizonte da psicanálise em extensão que se ata o círculo interior que traçamos como hiância da psicanálise em intensão" (LACAN, 1967/2003, p. 261). Anteriormente, no ato de fundação de sua escola, ele criara três seções que englobavam teoria, prática clínica e relação com ciências afins (LACAN, 1964/2003), levando os psicanalistas a se apropriarem dessa distinção para discutir a pesquisa em psicanálise.

\section{UM PERFIL DA PESQUISA PSICANALÍTICA NA UNIVERSIDADE}

Em relação às pesquisas psicanalíticas brasileiras, realizamos uma investigação que abrangeu todo o material disponível de teses, entre os anos de 1987 e 2012, no Banco de Teses da Capes, totalizando 1075 teses. Da leitura de seus resumos, compilamos os dados para fornecer uma análise descritiva e estatística. Posteriormente, realizamos exame de tema, método e autores de referência, encontrados em todos os resumos disponíveis. Algumas características do campo puderam ser apreendidas: maior quantidade de produção na região Sudeste, especificamente nos estados de São Paulo e Rio de Janeiro; financiamento da quase totalidade das pesquisas dos Programas de Pós-Graduação (PPG) específicos em psicanálise; teses distribuídas entre diversas áreas do conhecimento; predominância de temáticas teórico-clínicas (FONTELES, 2015). Encontramos também teses sobre e em psicanálise, que não restringem o campo a investigações clínicas. Se por um lado, a pesquisa é inseparável da clínica, por outro, não se limita a esta. Do mesmo modo, não pode prescindir de uma reflexão histórica e epistemológica, por sua vez, âmbito das investigações sobre psicanálise. Estes dados já foram discutidos em outro trabalho (FONTELES; COUTINHO, 2015). Neste, nosso foco recairá sobre os referenciais teóricos e métodos apresentados nas teses.

Em relação aos referenciais teóricos explicitados, a maior parte das teses cita Freud (421) e Lacan (331), seguidas de Winnicott (87), Klein (29), Bion (22) e Ferenczi (18) entre os autores da psicanálise, lembrando que uma tese frequentemente cita um ou mais autores. $O$ autor mais citado fora do campo psicanalítico é Foucault (21), seguido de Deleuze (10). A filosofia é o campo com a maior quantidade de autores referenciados (37 autores) depois da psicanálise (43), embora autores de outros campos como psicologia, literatura, artes, semiótica, sociologia/antropologia, linguística, história, educação e medicina também apareçam.

Os trabalhos presentes nos diversos PPGs fazem interlocução dos autores da psicanálise com os de suas respectivas áreas, mas o predomínio freudo-lacaniano é visível. De todo modo, é importante ressaltar que nem todas as teses declaram autor (353 teses); boa parte das teses com referencial freudiano e/ou lacaniano citam os dois; os trabalhos que fazem referência a autores anglo-saxões (Klein, Winnicott e Bion) se concentram nos PPGs paulistas. 
O que mais encontramos nas teses é a articulação entre Freud e algum outro teórico. Em relação aos autores psicanalíticos, encontramos associação entre Freud e Winnicott, Freud e Klein ou Freud e Lacan (mais encontrado) ou então Klein e Winnicott, Klein e Bion. Contudo, poucas teses relacionam autores psicanalíticos com paradigmas divergentes. Destacamos algumas, como exemplo: num PPG em psicologia, uma tese trabalha a noção de trauma articulando Freud, Ferenczi e Lacan; outra, cujo tema é a função paterna, num PPG em educação, utiliza Freud, Winnicott, Lacan e Piera Aulagnier; e uma sobre inibição intelectual, em um PPG em psicologia, opera um diálogo entre Freud, Lacan e Klein.

Em relação às teses dos PPGs específicos de psicanálise, há claro predomínio de Freud e Lacan como referência. $\mathrm{O}$ único autor além dos dois já citados é Ferenczi, que aparece em quatro teses. As maiores interlocuções são com autores da filosofia, tais como Foucault, por exemplo. Se tomarmos estes PPGs específicos, vemos em sua proposta pedagógica clara alusão aos referenciais freudo-lacaniano, o que impõe um limite, já na seleção, acolhendo projetos orientados por este referencial.

A partir deste achado, recorremos ao que diz Figueiredo em relação à chamada "era das escolas", ou seja, um período de grandes disputas entre kleinianos, freudianos e, posteriormente, lacanianos. Segundo ele, esse período já foi ultrapassado e a tendência atual é que autores contemporâneos produzam obras originais, sem a liderança de um movimento ou de uma nova escola. Há maior tendência à interlocução entre autores da psicanálise e um atravessamento de paradigmas: "A partícula 'e' no lugar do 'ou' aponta para o caráter complexo e paradoxal assumido pelas teorizações e estilos que então se forjam, desconstruindo as velhas oposições paradigmáticas" (2009, p. 14). Ele defende ainda que cultivar o pensamento psicanalítico não significa aderir a um sistema doutrinário, alinhado ao pensamento de Mezan (2014), para quem as fronteiras teórico-clínicas da psicanálise estão bem mais amplas do que na época de Freud, e os psicanalistas estão perdendo o medo de percorrer outras linhas de pensamento, buscando inclusive um common ground, apesar das diferenças.

De acordo com o material coletado nesta pesquisa, parece-nos haver um cuidado por parte dos autores das teses de não resvalar num ecletismo ou num "desfile de autores". A transferência de trabalho em relação a um teórico específico é forte no movimento psicanalítico, e uma "infidelidade" a determinados autores pode implicar na não aceitação ou não reconhecimento no campo. Embora muitos considerem a universidade um ambiente mais aberto que as escolas de psicanálise e com possibilidades maiores de diálogo, isto parece funcionar para as relações entre saberes diversos e referenciais de outros campos, mas não entre autores internos à psicanálise. No entanto, observamos um movimento, ainda que incipiente, de quebrar o paradigma dessa filiação única para propor diálogos contemporâneos. Se pensarmos que hoje as escolas de psicanálise disputam espaço na universidade, cada uma "luta" para conquistar seu território e alunos para suas formações.

Diversos autores apontam para a necessidade da autorização e do pensamento do psicanalista para além das filiações. Para Beividas (1999), a pesquisa em psicanálise fica submissa ao argumento de autoridade do autor que é colocado no lugar da verdade. Daí o excesso de transferência que ele encontra na pesquisa, criando uma subordinação que dá margem aos psicanalistas se entrincheirarem no que Freud ou Lacan disseram, submetendo a teoria ao argumento de autoridade, sem questioná-la. É justamente esse autorizarse mediante nomes próprios de autores canônicos que pode levar a uma reprodução de um saber totalizante e sem sujeito.

Haveria uma espécie de catecismo na formação dos analistas, dizem Safouan e Hoffmann (2015), tendo em vista que toda experiência institucional da psicanálise a transforma em um dogma a serviço da instituição. Desta forma, dissidentes, como Otto Rank e Sándor Ferenczi, são tratados como hereges. Assim, estes não somente são excluídos, mas também invisibilizados para não serem lidos, estudados. Neste sentido, os autores propõem não uma institucionalização da psicanálise, mas uma psicanálise para a instituição. A 
formação do analista seria antes um interesse do analista do que da instituição, em um modelo de escola mais aberto, sem tantas regras administrativas, sem tanta diferenciação entre seus membros.

Para Birman (2014a), o campo psicanalítico também se constituiu pela transferência ao saber analítico, aos grandes "mestres" da psicanálise. Isto produz um paradoxo, pois, ao tempo em que a experiência analítica pretende a produção e o reconhecimento da singularidade, a instituição analítica tende a excluir a diferença, como nos mostram os casos dos dissidentes clássicos. No entanto, os paradigmas no campo psicanalítico não podem ser avaliados como legítimos ou não pelo simples fato de serem incomensuráveis entre si. Ainda segundo o autor, dialogar com muitas tradições teóricas seria considerado uma resistência à psicanálise, uma vez que a interlocução teórica está marcada pela transferência. "Não poder transferir para diversas tradições analíticas se transforma num imperativo, qual seja, o de que se deve transferir para apenas uma das múltiplas tradições disponíveis" (BIRMAN, 2014b, p. 43, grifo do autor). A psicanálise reconhece a singularidade, mas no diálogo com as diversas linhas isso não ocorre. É a rigidez teórica da regra.

A proposta da psicanálise afasta-se do referencial binário cartesiano. Assim, é possível dizer que superar paradigmas e sistemas dogmáticos condiz com o fazer psicanalítico. Ainda sobre esta questão, Kupermann (2014) traz a ideia de uma transferência nômade no campo psicanalítico, não destinada a uma única filiação teórica ou institucional, mas a um pluralismo teórico-institucional, implicando resistência à submissão transferencial nas instituições psicanalíticas. Ressalta que pluralismo é diferente de ecletismo, também combatido por Freud, estando a transferência nômade entre a recusa do sistema totalizante e a recusa do ecletismo. $\mathrm{O}$ autor defende:

Para que a produção psicanalítica possa usufruir das virtudes da inserção acadêmica, seria preciso que os rituais, os dispositivos e as exigências que, na universidade, insistem em por à prova o narcisismo do pesquisador, ficassem imunes ao destino funesto da manipulação da transferência, preservando o pensamento nômade e o desejo de saber. (KUPERMANN, 2009, p. 306)

As primeiras institucionalizações da psicanálise (Sociedade Psicanalítica de Viena, IPA, Instituto de Berlim) foram sociedades fechadas e dogmáticas. Muitas escolas também recebem críticas em relação ao dogmatismo, na defesa do que seria a "verdadeira psicanálise". Isto nos faz interrogar: E a universidade? Seria a institucionalização da psicanálise dentro de moldes científicos ou um lugar onde a psicanálise pode estar com seu sistema próprio, desenvolvendo abertamente suas ideias? Como conciliar pesquisa científica e pesquisa psicanalítica?

Passemos às estratégias metodológicas. Nos resumos, encontramos referências a instrumentos de pesquisa, ao tipo de pesquisa ou a procedimentos de análise. Em relação ao tipo de pesquisa, poucos resumos explicitam método. Alguns falam em pesquisa teórica, teórico-conceitual, teórico-clínica ou estudo de caso. Encontramos também pesquisas ditas qualitativas, clínica-qualitativa, estudos longitudinais e etnopsicanálise, para citar os que se explicitam. Quanto aos instrumentos utilizados, levantamos uma grande quantidade de técnicas nos resumos das teses. Há predomínio de entrevistas e análise de casos clínicos, seguidos de análises de obras literárias, aplicação de testes psicológicos como HTP, TAT e Rorscharch, desenho-estória, observação participante e grupo focal, entre outros. Em relação a procedimentos de análise, destacamos análise do discurso, teoria dos campos, análise de conteúdo e uma única tese que aborda o tema da psicossomática e informa análise estatística, num PPG em psicologia.

Há claro predomínio de pesquisas teóricas, sobretudo nos PPGs de psicanálise. Nestes, 112 teses de um total de 125 nada dizem sobre o método, sendo que os 13 que o explicitam, referem estudos de casos clínicos. Um dado bastante relevante é o fato de 560 teses, mais da metade, não explicitarem, em seus resumos, qualquer menção ao método de pesquisa. 0 método tem sido frequentemente negligenciado pela psicanálise e a leitura dos resumos das teses nos deu a impressão de que os autores escrevem como se o método estivesse naturalmente implícito. Os psicanalistas, uma vez que estão inseridos na universidade, não escrevem somente 
para seus pares, mas para toda uma gama de leitores de diversas áreas. Mas o interessante desse fenômeno da não explicitação de métodos é o fato de que quase metade das teses em psicanálise não se encontra nos PPGs de psicanálise, nem nos de psicologia, mas dispersas em várias áreas. Isso mostra diferenças na elaboração de resumos, a partir da área. Somente para citar um exemplo, dentre as teses nos PPGs em medicina somente uma não descreve o método.

Ao nos depararmos com esta diversidade de pesquisas e instrumentos no levantamento e exames dos resumos das teses, algumas dúvidas apareceram: uma pesquisa com aplicação e análise de entrevistas seria uma pesquisa psicanalítica? Estaria a psicanálise importando métodos para ter lugar na universidade, para ser aceita pelas agências de fomento e conseguir financiamento para suas pesquisas, para publicar em periódicos não orientados pela psicanálise? Seria uma forma de submissão ou outra forma de apresentar-se? A psicanálise estaria submetendo-se aos ditames da ciência? Por que psicanalistas na universidade não se apropriam do método psicanalítico, no sentido de destacá-lo em suas produções, respaldando-o como método legítimo na produção de saber? As respostas a essas indagações dependem do que consideramos pesquisa em psicanálise.

Em muitos trabalhos de psicanálise, o método não se encontra esclarecido, em virtude do não entendimento de muitos pesquisadores do que seja uma pesquisa psicanalítica, do que pode ou não ser utilizado como instrumento, do que pode ou não ser feito, com o rigor necessário a uma investigação séria, $e$ que não pode ser confundido com rigidez. Muitas pesquisas clínicas partem da experiência do analista. Portanto, como traduzir um trabalho clínico - que nada tem a ver com protocolos formais de investigação científica, em geral cartesiano-positivistas - em uma tese? Estes questionamentos não são exclusivos da psicanálise, mas de todo campo que pressupõe ou acolhe outro paradigma de ciência, como o campo das humanidades e das artes.

O êxito de pesquisas desenvolvidas por analistas reconhecidos no campo mostra ser possível aproximações da psicanálise com outros métodos, sem perder o rigor concernente à investigação psicanalítica. Frente a críticas tão frequentes de submissão aos ideais da ciência, respondemos que esta seria mais uma forma de se apresentar, de fazer pesquisa, de conquistar espaço, diante de contestações, sobretudo àquelas advindas das ciências cognitivas. Articulações com outros saberes não são novidade para a psicanálise, considerando sua conformação interdisciplinar. Diálogos são imprescindíveis para a constituição, manutenção e alargamento do campo psicanalítico, no ambiente universitário ou fora dele.

\section{CONCLUSÃO}

A universidade impõe exigências à produção psicanalítica e que são importantes para que esta não se feche como dogma e não se torne imune a críticas. Isso não significa que não haja rigor a ser perseguido, ou que se possa dizer qualquer coisa, tendo como álibi a psicanálise aplicada (o que ocorre muitas vezes). Nomear uma pesquisa como sendo sobre psicanálise pode gerar, de certa forma, confusão de saberes e métodos sem o rigor analítico. Vejamos como Freud se posiciona:

A atividade psicanalítica é difícil e exigente, não pode ser manejada como os óculos que pomos para ler e tiramos para passear. Via de regra, ou a psicanálise tem o médico por inteiro, ou não o tem absolutamente. Os psicoterapeutas que se utilizam ocasionalmente da psicanálise, não se acham, pelo que conheço, em terreno psicanalítico firme; não aceitaram a análise inteira, mas sim a diluíram, tiraram-lhe o 'veneno' talvez. (FREUD, 1933/2010, p. 316)

Quando Freud recusa tirar o "veneno" da psicanálise, lembramo-nos de Althusser (1966/1993) e sua hipótese sobre as tentativas de anexação da psicanálise a outros saberes, justamente por seu caráter virulento. Ser absorvida pela medicina, ou por qualquer outro campo, é a estratégia utilizada para retirar da psicanálise seu caráter subversivo. Ela se tornaria, então, uma técnica terapêutica adaptativa para ser digerida e aceita pelas normas estabelecidas. 
Essa disputa pela verdade é inerente a ambientes universitários que promovem "uma luta para saber quem, no interior desse universo socialmente mandatário para dizer a verdade sobre o mundo social (e sobre o mundo físico), está realmente (ou particularmente) fundamentado para dizer a verdade" (BOURDIEU, 2004, p. 116). É o que o autor denominou de espaço de violência simbólica, ou seja, a imposição de significados como legítimos, levando em consideração que a dominação simbólica, no âmbito da universidade, tem sido referenciada na autoridade da ciência. Há "violência simbólica" tanto em relação à apropriação da psicanálise por outros campos, quanto na apropriação de outras teorias pela psicanálise.

A psicanálise tem reconhecido a universidade como lugar de pertencimento, ressaltando as particularidades de seu método e de seus parâmetros de rigor, distantes do modo de produção hegemônico das ciências no ambiente universitário, no qual o ideal da neutralidade científica resulta em apagamento do sujeito, tão caro à psicanálise. Pode-se pensar que a psicanálise não se submete ao rigor metodológico das ciências positivistas, desde Freud. Contudo, o rigor ético desta práxis pode sustentar outro modo de produzir ciência. Paradoxalmente, vemos que a psicanálise na universidade acaba, por vezes, submetendo-se às regras de padronização. Daí resultam conflitos em se produzir pesquisa em psicanálise, com base em outra perspectiva epistemo-metodológica. Apesar dessas dificuldades, um fato concreto se impõe: a ampla produção de investigações em e sobre psicanálise nas universidades e o desafio de conduzir pesquisas psicanalíticas sem perder de vista o sujeito e a presença do inconsciente. Estas questões merecem um aprofundamento que, no entanto, estão além dos objetivos deste trabalho.

A psicanálise se constitui na dimensão de pesquisa, reformulando-se continuamente, como atesta o vasto legado de Freud e dos que vieram depois e sustentam a possibilidade de transmissão da psicanálise, dentro e fora da universidade. O caráter de inacabamento, constitutivo de seu referencial, permite dizer que na universidade, lócus tradicional da pesquisa, a psicanálise pode ser formulada e aí também reinventada. Ou, seguindo o que o próprio Freud disse a respeito do seu ensino: “Mas não entendam este meu anúncio como se eu pretendesse dar palestras dogmáticas e requerer sua fé condicional. Esse mal-entendido seria uma grave injustiça contra minha pessoa. Não quero despertar convicções - quero fornecer estímulos e abalar preconceitos" (FREUD, 1917/2014, p. 325).

Recebido em: 30 de junho de 2016. Aprovado em: 30 de dezembro de 2016.

\section{REFERÊNCIAS}

ALTHUSSER, L. Trois notes sur la théorie des discours (1966). In: Paris: Stock/IMEC, 1993. Écrits sur la psychanalyse.

ASSOUN, P-L. Freud: a filosofia e os filósofos. Rio de Janeiro: Francisco Alves, 1978.

BEIVIDAS, W. O excesso de transferência na pesquisa em psicanálise. Psicologia Reflexão e Crítica, v. 12, n. 3. Porto Alegre: Universidade Federal do Rio Grande do Sul, 1999.

BIRMAN, J. Arquivo e memória da experiência psicanalítica: Ferenczi antes de Freud, depois de Lacan. Rio de Janeiro: Contra-Capa, 2014b.

. Os paradigmas em psicanálise. In: BIRMAN, J.; KUPERMANN, D.; FULGÊNCIO, L. (orgs.). A fabricação do humano: psicanálise, subjetivação e cultura. São Paulo: Zagodoni, 2014 a.

BOURDIEU, P. Coisas ditas. São Paulo: Brasiliense, 2004.

COLONOMOS, F. Présentation. In: On forme des psychanalystes. Rapport original sur les dix ans de I'Institut Psychanalytique de Berlin 1920-1930. Paris: Denoël, 1985.

FIGUEIREDO, A. C. Psicanálise e universidade: reflexões sobre uma conjunção ainda possível. Fractal: Revista de Psicologia, v. 20. n. 1. Niterói: Universidade Federal Fluminense, 2008, p. 237-252.

FIGUEIREDO, L. C. M. A psicanálise e a clínica contemporânea. Contemporânea - Psicanálise e Transdisciplinaridade, v. 7. Porto Alegre: Contemporâneo - Instituto de Psicanálise e Transdisciplinaridade, 2009, p. 9-17.

FONTELES,C. Psicanálise e universidade: uma análise da produção acadêmica no Brasil. Tese de doutorado, Programa de Pós-Graduação em Psicologia, Instituto de Psicologia, Universidade Federal da Bahia e Université Paris 7, 2015. 
FONTELES, C.; COUTINHO, D. Recherche en psychanalyse: le champ psychanalytique dans les universités brésiliennes. Reherches en Psychanalyse, v. 20. Paris: Association Recherches en psychanalyse, 2015, p. 179-189.

FREUD, S. A questão da análise leiga: conversações com uma pessoa imparcial (1926) Rio de Janeiro: Imago, 1996. (Ed. standard brasileira das obras completas, 20).

Autobiografia (1925) São Paulo: Companhia das Letras, 2011. (Sigmund Freud obras completas, 16).

. Conferências introdutórias à psicanálise (1917) São Paulo: Companhia das Letras, 2014. (Sigmund Freud obras completas, 13).

Contribuição à história do movimento psicanalítico (1914) São Paulo: Companhia das Letras, 2012. (Sigmund Freud obras completas, 11).

Deve-se ensinar a psicanálise nas universidades? (1919) São Paulo: Companhia das Letras, 2010. (Sigmund Freud obras completas, 14).

Introdução ao narcisismo (1914) São Paulo: Companhia das Letras, 2010. (Sigmund Freud obras completas, 12 ).

Novas Conferências introdutórias à psicanálise (1933) São Paulo: Companhia das Letras, 2010. (Sigmund Freud obras completas, 18).

Os instintos e seus destinos (1915) São Paulo: Companhia das Letras, 2010. (Sigmund Freud obras completas, 12)

Princípios básicos da psicanálise (1913) São Paulo: Companhia das Letras, 2010. (Sigmund Freud obras completas, 10).

Recomendações ao médico que pratica a psicanálise (1912) São Paulo: Companhia das Letras, 2010. (Sigmund Freud obras completas, 10).

Psicanálise e teoria da libido (1923) São Paulo: Companhia das Letras, 2011. (Sigmund Freud obras completas, 15$)$

HOFFMANN, C.; BIRMAN, J. L'autonomie des universities et la nouvelle condition étudiante. La célibataire, v. 23, Paris: EDK, 2011, p.55-62.

HOFFMANN, C. Formation, recherche et instituition. In: CHEMAMA, R.; HOFFMANN, C. (Eds.), Pratique psychanalytique et politique. Paris: Hermann, 2013.

KUPERMANN, D. Sobre a produção psicanalítica e os cenários da universidade. Psico, v. 40, n. 3. Porto Alegre: Pontifícia Universidade Católica Rio Grande do Sul, 2009, p. 300-307.

Transferências cruzadas. Uma história da psicanálise e suas instituições (2a ed.). São Paulo: Escuta, 2014.

LACAN, J. Ato de fundação (1964). In Outros escritos. Rio de Janeiro: Jorge Zahar, 2003.

Proposição de 9 de outubro de 1967 sobre o psicanalista da escola (1967). In: Outros escritos. Rio de Janeiro: Jorge Zahar, 2003.

MEZAN, R. O tronco e os ramos: estudos de história da psicanálise. São Paulo: Companhia das Letras, 2014.

SAFOUAN, M.; HOFFMANN, C. Questions psychanalytiques. Paris: Hermann, 2015

SOKOLOWSKY, L. Freud et les Berlinois. Du congrès de Budapest à I'Institut de Berlim 1918-1933. Rennes: Presses Universitaires de Rennes, 2013.

SOUSA-SANTOS, B.; ALMEIDA-FILHO, N. A universidade no século XXI: para uma universidade nova. Coimbra: Almedina, 2008.

WIDLÖCHER, D. L'instituition psychanalytique et la recherche. In: EMMANUELLI, M.; PERRON, R. (orgs.). La recherche en psychanalyse. Paris: Presses Universitaires de France, 2007.

\section{Camila Santos Lima Fonteles}

camilafonteles@hotmail.com

Denise Maria Barreto Coutinho

denisecoutinho1@gmail.com

Christian Hoffmann

hoffmann.ch@wanadoo.fr 